\title{
Students Perception of Moral Education Textbooks Design Components and Learnability
}

\author{
Mohamed Hilmie Mohd Mokhtar ${ }^{1}$, Maizura Yasin ${ }^{1}$ \\ ${ }^{1}$ Faculty of Educational Studies, Universiti Putra Malaysia, Serdang, Selangor, Malaysia \\ Correspondence: Maizura Yasin, Faculty of Educational Studies, Universiti Putra Malaysia, 43400 UPM Serdang, \\ Selangor, Malaysia. Tel: 603-9769-8210. E-mail: y_maizura@upm.edu.my
}

Received: September 3, 2021

Accepted: September 28, 2021 Online Published: October 16, 2021

doi:10.5539/ass.v17n11p182

URL: https://doi.org/10.5539/ass.v17n11p182

\begin{abstract}
Textbooks are one of the most fundamental learning and teaching tools used in schools all around the world (Nicholls, 2003). Today's technology allows students to access a variety of textbook formats, including online textbooks that they may read from anywhere. This study looks into the style and arrangement of learning textbooks in Malaysia in order to make studying more convenient. The purpose of this research is to see if the dynamics of textbook layout affect students' desire to learn. Thirty Year 6 children from a primary school in the Selangor district of Hulu Langat participated in this study. Students' views of textbook design elements, such as paper quality, printing, colour, and pedagogical aspects, were determined using a quantitative survey. Print and colour were scored higher by the students than paper quality, artwork, and images, according to the data. Furthermore, the research discovered a link between the layout of a book and its actual use.
\end{abstract}

Keywords: moral education, textbooks, design, learnability, students

\section{Introduction}

Textbooks are an essential element of the educational environment since they serve so many functions. Textbooks are viewed as the essence of the curriculum by teachers, who teach their pupils the complete material of these volumes from cover to cover. For students, textbooks do more than just summarise the subject's material at their grade level. In this regard, textbooks are organised and illustrated, providing a structure and reinforcement to students' learning (Miller \& Berry, 1962). Textbooks have become the curricular guideline and evaluative reference point for education authorities and school administrators.

A textbook's key components are the content, the organisational structure of ideas, and the concepts to be taught. On the other hand, the design of school textbooks is more than just a matter of aesthetics (Neill, 1982). Most textbooks also include important elements like glossaries, pertinent images, and instructors' comments, making them valuable educational aids for teachers. As a result, textbooks have become a type of unified instructional resource for all stakeholders. In contrast, unsuitable textbook design and features may be harmful to students' learning and engagement, rendering this resource useless (Harp \& Mayer, 1997). In this sense, the need to make textbooks attractive has spawned an entire discipline called instructional design.

This is a major advancement since reading texts is mostly a visual task with psychological ramifications. To that aim, textbook design has evolved into a branch of science, with textbooks increasingly being created and produced using tried-and-true methods. However, there is still a difference in textbook design and usage between rich and underdeveloped countries. There are several causes for variations in textbook design and use between nations. In most educational systems, textbooks are the most common tool in educating learners. The majority of textbooks add visual images with the aim of helping students have a thorough understanding of topics and contents of lessons. These visual images such as pictures, photos and paints, etc. are adopted to transmit the information of different matters.

Visual grammar describes how language specialists utilise visual and verbal imagery to express meaning. Visual communication is related to framing, colour saturation, and semiotic modality.Textbooks are educational resources that deliver knowledge in a systematic and straightforward fashion. When two semiotic resources are utilised simultaneously, it is essential to understand how visual pictures interact with verbal texts in discourse meaning formation. Textbooks are required reading for non-native speakers of Persian at Iranian colleges and 
institutions (Ahmadi et al., 2019).

Malaysia, a developing nation, confronts a number of challenges when it comes to textbook preparation. There is a consensus that textbooks are necessary tools in supporting students' learning and serve as a guideline for inexperienced teachers. However, taking the analogy of textbooks as a backbone of classroom instruction, it would not be wrong to say that the teaching and learning process is particularly wasted in the Malaysian school context. Textbook development and design are the responsibility of government authorities. Textbooks have become the sole learning resource in government schools. In many cases, the textbooks provided do not have supplementary resources such as teacher guides and reference books (Vellenga, 2004).

Furthermore, difficulties such as printing delays, paper procurement failures, and printing mistakes raise worries about the quality of textbooks used in public and private institutions. Nonetheless, under the affiliation of the government test board, end users are frequently harmed by these issues. Therefore, it is worth examining the link between textbook design and students' interest in learning at the primary level. Based on the discussion above, this study aims to identify students' perceptions on textbooks' layout and organization and whether textbooks ease learning. While recent technological advancements have enabled instructors to innovate and achieve new goals, published textbooks remain the most frequently utilised source materials for the majority of educational settings. In language education, the situation is similar, and several new commercial textbooks are released on a monthly basis to address changing instructional focuses and evolving linguistic requirements of learners. As a result of this circumstance, it is critical to determine which language textbooks are most appropriate for pupils in specific contexts. To put it another way, regardless of whether one recognises the worth of textbooks, they meet an acceptable standard or degree of quality and popularity among learners. (Ansary \& Babaii, 2002).

\subsection{Research Objective}

The objective of this study is to examine students' views on the technical design aspects of textbooks, such as print and paper quality, illustrations, pictures, colours and presentations, and graphic materials used in the textbook and whether these elements lead to learnability in the moral education subject.

It is hoped that the findings will provide an overview of the use of textbooks towards the teaching and learning process of effective moral education and promote student learning.

Among the specific objectives of this study are:

i. To determine the perception towards design components of the moral education textbook among Year 6 students in a primary school in Hulu Langat.

ii. To determine the perception towards learnability of the moral education textbook among Year 6 students in a primary school in Hulu Langat.

\subsection{Research Question}

i. What is the students' perception towards the design components in the Year 6 moral education textbook?

ii. What is the students' perception towards the learnability of the Year 6 moral education textbook?

\subsection{Literature Review}

There are three textbook design principles that might potentially have a positive impact on discussions regarding textbook layout and usability. The first of the two textbook design theories is the generative theory Lavrenko, V. (2008). The notion states that how a reader understands the meaning of a text is affected by its design elements. According to this notion, learning is a building project in which every piece of knowledge is utilised to build cognitive links. Thus, visual attention to represented materials is a critical component in the learning process when it comes to constructing information from visuals in geography textbooks. Specifically, educational psychology research indicates that information acquisition is more successful when visuals and text are combined (multimedia effect) than when text or images are used alone (Mayer 2009, Eitel et al. 2013). The efficacy of this approach is improved if it is accompanied with visual aids on a page or if students can see the pictures mentioned in the text. It has been shown that images with captions or labels are crucial in research, and that students will more easily memorise and recall them than they will ordinary text and illustrations, even when the two are put extremely near together on the page.

Harp and Mayer (1997) examined the impact of images on the learnability of scientific texts, employing the same scientific content as in the prior study. They argued that some elements, such as images and language, are attractive. In this light, images and phrases are placed on the page to stimulate readers' interest. On the other hand, these subtleties serve to distract the student rather than assist in concept understanding and subsequent issue resolution. The research classified textual elements into two categories: emotional and cognitive 
information. While attractive and amusing, it has been said that drawings are pedagogically ineffective since they serve just to increase the users' emotional interest. On the other hand, images with captions or reduced explanatory text are much more conducive to understanding and therefore have a cognitive appeal.

A second hypothesis focuses on the reader. The idea of a novel way to establish cognitive connections while reading is a generative theory extension. This concept assumes that a text's significance is hidden inside it. Instead, the reader deduces it from the text. Because the context of the book's creation and the reader's motives influence how the text is interpreted, both must be examined (Weinberg \& Weisner, 2011). The idea proposes three types of readers: implicit, deliberate, and empirical. The writers used the term "code" to describe how readers might understand a work. Readers tend to interpret content based on its context, which is set by the language employed. Weinberg and Weisner (2011) state that a math student must grasp the textbook's code, symbols, and vocabulary. This code is designed to handle the particular conditions students experience as readers. Students who don't grasp the coding may not be able to use the book's layout or the book's format as intended. The study's subjects may not understand the suggested codes as well as professional readers.

Examples of textbook design and illustration philosophies include verbal learning, reinforcement, and organic reading. Smith (1960) embraced the functional or organic idea by establishing a set of scientific textbook design guidelines. The printing technique and materials utilised, the subject matter's demands, and verbal and nonverbal study behaviour and communication processes all impact the design and artwork of a textbook. Designers must use communication methods to produce impressionistic, abstract, and representational art that fulfils student demands for visual appeal, topic knowledge, content retention, creativity, and textbook organisation. This paper deliberates and examines Mayer, Steinhoff, Bower, and Mars (1995) and Harp and Mayer (1997).

Several studies have looked into how students view the relationship between textbook layout and their ability to study (Lan-drum \& Clark, 2006; Landrum, Gurung, \& Spann, 2012; Weiten, Guadagno, \& Beck, 1996). A variety of research papers are focused on textbooks used in college-level psychology courses. This lack of study on textbook layout perceptions at both elementary and secondary levels has resulted. According to Weiten, Guadagno, and Beck (1996), textbooks may be made more expensive and more informative by their pedagogical aids. Thus, only they should be included if they improve student learning. By definition, textbooks seek to condense and interpret a discipline's knowledge and study. They try to give a sufficient breadth and depth of coverage of a topic so students may begin to comprehend what the discipline is about, as well as the techniques and scholarship that support it. Thus, textbooks represent what is known about a field, according to the audience's requirements, knowledge, and maturity.

Thus, textbooks serve as a standard resource, reference, and teaching tool, and it is unsurprising that teachers teach and students learn from these instructional materials (Woodward, 2012). According to Gurung (2003), pupils who felt that keyword introduction was beneficial were less likely to succeed. The findings indicate that students' views of their learning environment may not necessarily mirror their ability to retain information. Textbooks are critical components of the teaching and learning process since they are the primary means by which knowledge is conveyed to students. Additionally, one of the fundamental purposes of textbooks is to make existential information accessible and obvious to the student in a selective, easy-to-understand, and structured manner. The textbook plays a critical and beneficial role in teaching and learning. They assert that textbooks supply the required input for classroom learning via various exercises, readings, and explanations. As a result, they will always survive on the basis of their ability to satisfy certain requirements (Tok, 2010).

It is generally acknowledged that teachers at the elementary and secondary levels have a heavy burden in the evaluation of textbooks. The important job of conducting a comprehensive assessment is made simpler with the aid of checklists and rubrics. The research team of Mahmood, Iqbal, and Saeed (2009) established a rubric to rate textbook quality, based on the eight qualities Garvin (1987) suggested for superior goods. Three variables most commonly used to evaluate the arrangement of a textbook were the aesthetics, the perceived value, and durability. One of the few original ideas in Malaysia, using this standard, particularly to review student views of textbook design, is worth pursuing.

On the other hand, Weiten et al. (1996) looked at 13 widely used pedagogical aids, including chapter summaries and learning objectives, technical terminology in bold and pronunciation guides, chapter glossaries, review activities and learning checks. The most highly valued components in this category are technical terminology, chapter summaries, and running and chapter glossaries. Learning goals and pronunciation standards were disliked. Student grades and material evaluation had little connection. According to Weiten, a textbook is created with students' views in mind, not teachers' (1998). Applied academic studies can benefit from this strategy.

An objective analysis, teacher surveys, and student involvement research are three techniques used by Landrum 
et al. (2012). Another technique is to study student responses and how preferences and self-reporting relate to course grades. Landrum, Gurung, and Spann (2012) used the CSAT and TAUS to measure student comprehension (1996). Purchased textbooks were more likely to be read, the authors suggest. These are textbook components that students read. Details about textbook design and utility. Adopting these methods in Malaysian schools and student views has drawbacks.

\section{Method}

The quantitative survey research design was utilised in this investigation. Students' views of Moral Education textbooks used in elementary schools were investigated using a questionnaire. The data was analysed utilising the basic descriptive technique since the study's premise is more general than speculative. Non-probability sampling, especially the handy sampling technique, was used for the sampling. The sample of the study includes 30 primary school students in Year 6 in Hulu Langat area who are taking Moral Education classes.

\subsection{Item Reliability}

Cronbach's Alpha scores, which range from 0.00 to 1.0 , were used to evaluate the survey instrument's reliability. A number that is close to 1.0 denotes high dependability. A number around 0.00 , on the other hand, indicates that an instrument is unreliable (Yusof, 2004). The range of scores and the degree of dependability are shown in Table 1. Cronbach's Alpha was found to be 0.98 in this research. Table 1 shows that a high value implies more dependability. As a result, it may be inferred that the instrument is successful and consistent, and that it can be utilised for study (Bond \& Fox, 2015).

Table 1. Interpretation Cronbach's Alpha Score (Bond \& Fox, 2015)

\begin{tabular}{ll}
\hline Cronbach's Alpha Score & Level of reliability \\
\hline 0.8 to 1.0 & Very good and effective with a high degree of consistency \\
0.7 to 0.8 & Good and acceptable \\
0.6 to 0.7 & Acceptable \\
$<0.6$ & The item needs to be repaired \\
$<0.5$ & Items need to be dropped \\
\hline
\end{tabular}

Table 2 summarises the level of respondent's reliability value (person reliability) that can be accepted. Furthermore, according to Linacre (2005), the value exceeding 2.0 represents a good isolation index. For this study, the value of the respondent's reliability is 0.97 and the separation index (separation index) obtained is 5.65 , exceeding the value of 2.0 .

Table 2. Reliability Values (Cronbach's Alpha) and Reliability Values and Respondent Isolation for the entire Instrument construct

\begin{tabular}{cc}
\hline $\begin{array}{c}\text { Isolation of Respondents } \\
\text { (Separation Index) }\end{array}$ & $\begin{array}{c}\text { Respondent reliability value } \\
\text { (Person Reliability) }\end{array}$ \\
\hline $5.65 \quad$ Cronbach's Alpha reliability value $=0.98$ & 0.97 \\
\hline
\end{tabular}

Table 3 summarises the statistics of the reliability value and item reliability. The study's item reliability value is 0.94, which exceeds the value of 0.80 . This indicates that the item is in good condition and acceptable (Bond \& Fox, 2015). Meanwhile, the item separation value (item separation) is 4.06, indicating that it is good. As mentioned by Linacre (2005), a value exceeding 2.0 indicates a good index separation.

Table 3. Reliability values and Item Isolation for the entire Instrument Construct

\begin{tabular}{cc}
\hline $\begin{array}{c}\text { Item Separation } \\
\text { (Separation Index) }\end{array}$ & $\begin{array}{c}\text { Item reliability value } \\
\text { (Item Reliability) }\end{array}$ \\
\hline 4.06 & 0.94 \\
\hline
\end{tabular}

After conducting numerous investigations concentrating mainly on textbook characteristics, the researcher created a six-item measure that was evaluated and accepted by expert researchers. There were two parts to this scale: 
There are a number of demographic questions in Section A, such as what your age, gender, and current location are. The significance of print and paper quality, as well as the usage of colour in textbooks, were discussed in Section B. In addition, the participants were asked to evaluate the textbook's characteristics. General layout, cover, title page, table of contents; index; glossary; appendices; chapter layout, including chapter aims, summary, introduction; information boxes; activities; and questions. Textbook usage frequency and student assessments of visual stimulation levels were also addressed. The respondent was asked for their informed verbal permission, and they were instructed about the scale's items, with any misunderstandings explained appropriately. The poll was conducted entirely online using Google Forms. Respondents will fill out a google form to answer the question. The survey took an average of 15 minutes to complete for each student. All completed forms were coded and subjected to a data cleansing procedure, with numerical and category values given to the answers. Simple descriptive tests were run on this data using the SPSS 17.0 software.

\section{Results}

\subsection{Quality of Print, Paper, and Colour}

The respondents rated the quality of print as more essential than the kind of paper used to print the Moral Education textbook. The respondents ranked the importance of colour in visuals (pictures, charts, and diagrams) as the highest, learning aids (for coding, classification, and informative categorization) as fairly significant, and information presentation as the lowest (Table 4).

Table 4. Percentage of Perceived on The Importance of the Quality of Print in Textbooks

\begin{tabular}{|c|c|c|c|}
\hline How important do you consider the following features in a textbook? & $\begin{array}{c}\text { Not } \\
\text { important }\end{array}$ & $\begin{array}{l}\text { Somewhat } \\
\text { important }\end{array}$ & $\begin{array}{c}\text { Very } \\
\text { important }\end{array}$ \\
\hline Quality of print, font, type, graphics & & $\begin{array}{c}17 \% \\
(5)\end{array}$ & $\begin{array}{l}83 \% \\
(25)\end{array}$ \\
\hline Quality of paper used for printing & $\begin{array}{c}17 \% \\
(5)\end{array}$ & $\begin{array}{c}17 \% \\
(5)\end{array}$ & $\begin{array}{l}66 \% \\
(20)\end{array}$ \\
\hline Colour presentation of information & & & $\begin{array}{c}100 \% \\
(30)\end{array}$ \\
\hline Graphics, Pictures, charts, diagrams & & & $\begin{array}{c}100 \% \\
(30)\end{array}$ \\
\hline $\begin{array}{c}\text { Colour as a learning aid including coding, classification, and } \\
\text { categorisation of information }\end{array}$ & & $\begin{array}{c}17 \% \\
(5)\end{array}$ & $\begin{array}{l}83 \% \\
(25)\end{array}$ \\
\hline
\end{tabular}

Based on the table above, $100 \%$ of the respondents ranked the elements of colours used to present information and graphics, pictures, and charts as very important. This finding suggests that the use of color in presenting compelling information positively affects students' interest towards the moral education textbook. In addition, $83 \%$ of the respondents ranked learning aid, including coding, classification, and categorization of information and quality of the print, font, type, graphics, as the most important, while $17 \%$ ranked these elements as somewhat important. Next, $66 \%$ of respondents said the quality of paper used for printing is very important, $17 \%$ ranked this element as somewhat important, and $17 \%$ ranked it as not important.

\subsection{Satisfaction towards Book and Chapter Layout Features}

$100 \%$ of respondents evaluated the functioning of their textbooks' cover, title page, table of contents, and index as good. Meanwhile, $83 \%$ of respondents said their textbook glossaries and appendices were sufficient. Additionally, $100 \%$ of respondents thought that their textbook's chapter introductions, exercises, boxes (with recommendations, additional material, and internet sources), and questions functioned well. Finally, as shown in Table 5, all respondents felt that the chapter objectives and summaries in their textbook were good and helpful.

Based on the table above, 100 respondents are satisfied with the book's cover, title page, and table of content. All of them are also satisfied with the appendix. Meanwhile, $83 \%$ of the respondents are satisfied with the glossary in the textbook, while $17 \%$ are dissatisfied. Finally, $100 \%$ of the respondents are satisfied with the chapter layouts, objectives, introduction, boxes, and additional information. These findings indicate that the students are satisfied with the chapter layout and found this element is helpful in their learning. 
Table 5. Satisfaction of the Book and Chapters Layout Features

\begin{tabular}{|c|c|c|c|}
\hline $\begin{array}{l}\text { How would you generally rate the following } \\
\text { features of your textbooks? }\end{array}$ & Do not exist & $\begin{array}{l}\text { Present but } \\
\text { unsatisfactory }\end{array}$ & Good functional \\
\hline \multicolumn{4}{|l|}{ Book layout } \\
\hline Cover and title page & & & $\begin{array}{c}100 \% \\
(30)\end{array}$ \\
\hline Table of contents & & & $\begin{array}{c}100 \% \\
(30)\end{array}$ \\
\hline Indices of the respondents own textbook & & $\begin{array}{c}17 \% \\
(5)\end{array}$ & $\begin{array}{l}83 \% \\
(25)\end{array}$ \\
\hline Glossary of the respondents own textbook & & $\begin{array}{c}17 \% \\
(5)\end{array}$ & $\begin{array}{l}83 \% \\
(25)\end{array}$ \\
\hline Appendix & & & $\begin{array}{c}100 \% \\
(30)\end{array}$ \\
\hline \multicolumn{4}{|l|}{ Chapter layout } \\
\hline Objectives of the chapters & & & $\begin{array}{c}100 \% \\
(30)\end{array}$ \\
\hline Introduction & & & $\begin{array}{c}100 \% \\
(30)\end{array}$ \\
\hline Boxes, additional information & & & $\begin{array}{c}100 \% \\
(30)\end{array}$ \\
\hline
\end{tabular}

\subsection{Perceptions of Learnability}

As shown in (Table 6), a substantial proportion of respondents think their textbook is aesthetically engaging. Meanwhile, there is little distinction between individuals who think their textbooks make learning simple and those who believe otherwise. In this view, the majority of students believe that the organisation of their textbooks facilitated revision. Additionally, $83 \%$ of respondents confessed to often referring to their textbooks (Table 7) for casual or independent reading as well as for assistance in completing teacher-assigned tasks or projects.

Table 6. Student perceptions of learnability

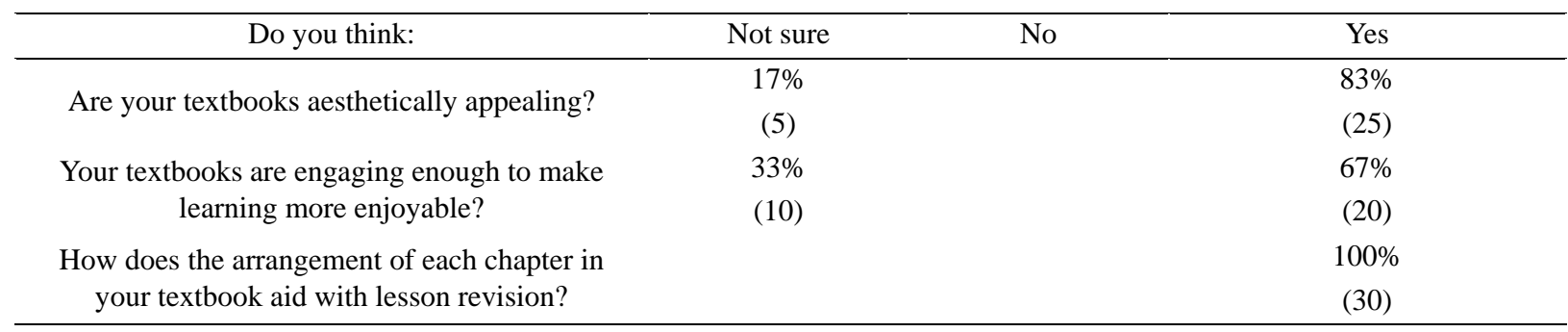

Table 7. Student responses to the frequency of textbook use

\begin{tabular}{|c|c|c|c|}
\hline How often do you study from your textbooks: & Never & Seldom & Frequently \\
\hline \multirow{2}{*}{ Independent } & & $33 \%$ & $67 \%$ \\
\hline & & $(10)$ & $(20)$ \\
\hline In accordance with teachers & & $17 \%$ & $83 \%$ \\
\hline reading assignments & & $(5)$ & $(25)$ \\
\hline
\end{tabular}

As shown in Table 6, 100 per cent of the respondents strongly agreed that the chapters in the textbook help in their revision. In addition, 83 per cent of respondents agreed that the textbook is visually stimulating, and 17 percent were unsure. 67 per cent of respondents agreed that textbooks increase their interest and make learning easier, while 33 percent were not sure.

Regarding the frequency of textbook use, 67 per cent of the respondents often use textbooks independently to review lessons, while 33 per cent shared that they seldom use textbooks to study. Furthermore, 83 per cent of 
students agreed that they often use their textbook as a reference to complete their assignments, while 17 percent of student's seldomly use textbooks as a reference. This indicates that students will use their textbooks more often to complete the assignments given by the teacher.

\section{Discussion}

Based on the survey's findings, the following things should be highlighted. To begin with, the findings of the research show that primary children value better textbook print and vivid images above high quality paper. Second, pupils are pleased with the textbook's chapter arrangement. Third, the connection between textbook layout perception and use rate does not seem to be obvious in this research. The overall impression of the textbook layout among the students polled, on the other hand, is favourable.

The first result goes against popular belief about the significance of paper quality. Nonetheless, it may be of interest to education authorities who are responsible for budgetary planning in the field of education. If this result can be extrapolated to a wider population, cost-cutting may begin by utilising lower-quality paper and redirecting resources to more efficient textbook design and printing. Furthermore, this result suggests the necessity for a stronger customer focus from a commercial standpoint in the context of students as customers, particularly in the private sector. Another consequence of this result is that textbook design should be reoriented. Because students valued print and visual aspects above paper quality, switching from paper-based textbooks to e-books or electronic resources may be a sustainable and cost-effective shift.

The second result is important in the context of learning in general. In light of earlier results (Weiten, Guadagno, \& Beck, 1996), it is clear that elementary school children valued layout elements such as chapter summaries on a par with older respondents in past research. This shows that elementary kids are becoming more mature, and it provides insight into the psychology of learning at both the pre- and post-adolescent stages.

The third result is consistent with previous research that has looked beyond the usefulness of physical characteristics to the psychological aspects of textbook use. Giordano (1982) argued that even if a textbook's layout is very successful, it may still be inappropriate if it is fundamentally different from the layout of other textbooks in use. Furthermore, if map reading is not taught, important elements such as a map may become more of a learning stumbling block. Furthermore, when considering a textbook as a whole, Geertsen (1977) stated that the significance of students' motivation in utilising a textbook reading is just as important as the layout of the textbook.

Although results one and three seem to be unrelated at first glance, when taken together, they confirm the theoretical implications of emotional and cognitive motivation to learn. While the majority of students valued colourful images and found their textbooks aesthetically engaging, the result may have little impact on desire to study other topics. Harp and Mayer (1997), on the other hand, found that applying this result to additional topics is appropriate.

The following are general descriptions of the textbooks in question: (a) The pictures in this book are mainly ornamental. This explains the little difference in learning ability between those who did and those who did not. The aesthetic features of these textbooks primarily appeal to students on an emotional level, but their effect on their cognitive interest is yet unknown. Teachers' outstanding teaching abilities and competence in utilising the textbook to teach new topics and ideas may explain the favourable reaction to the effect on chapter arrangement in learning. This result emphasises the need of examining textbook design in its proper context. It is essential to view the function of a teacher as a mediator.

For obvious reasons, historically linear, text-based, teacher-centric textbooks that force teachers to pay careful attention to the books' content and pedagogy as well as to be extra-creative with teaching strategies and in using a variety of strategies to make up for the textbooks' inadequacies just won't cut it anymore (Giordano, 1982). In order to properly evaluate the results of a research, it is necessary to look at the findings in context, as well as to understand how textbooks' layouts could affect classroom dynamics. Although this is not the first study of its type to be conducted in Malaysia, the findings may open the door for further research in this field. By putting students at the centre of textbook creation, we can ensure that textbooks are more valuable as teaching and learning aids.

\section{Implication Toward Educational System in Malaysia}

Textbooks can help achieve teaching and learning objectives when the materials are appropriate to students' levels and needs. The types of materials in a textbook are main contents, exercises, and activities. Teachers can ensure the materials suit students' ability by using the materials directly, modifying, or supplementing with additional materials if the available material is not enough for students to master the skills. 
According to Gopinathan (1983), textbooks are widely used in the classroom, despite the innovation of more sophisticated teaching aids in the information technology era. Textbooks are important learning tools and are difficult to replace with other materials. Therefore, textbooks play an important role in the education system in Malaysia. It is acknowledged that although despite the various modern and sophisticated teaching aids available in today's information technology era, we cannot ignore the role of textbooks. Realising its importance, the Ministry of Education has issued directives on using textbooks as the main resource in the classroom. Many studies show a positive effect between the use of textbooks and student academic achievement. From the teachers' perception, many teachers have recognised the importance of textbooks as a teaching and learning resource.

Given the important role of textbooks in the Malaysian education system, it is suggested that a more detailed study can be conducted by certain parties, especially the Education Resources and Technology Division (BSTP) of the Ministry of Education, to see the level of quality of textbooks and suitability and its use in the teaching and learning process. The study could involve samples from various parties such as teachers, parents, or guardians of students and students who cover a wider geographical zone to further increase the study's reliability, validity, and accountability. Surveys can also be conducted on respondents from different schools like private schools, and comparisons about their levels of feedback or views could be done.

\section{Conclusion}

To summarise, the physical characteristics of textbooks, particularly their print, chapter structure, and vibrant pictures, are critical for primary school pupils. In this perspective, there will always be opportunity to improve textbook design by concentrating on factors such as simplicity of use, textbook sustainability as a resource, and economics. This research of Year 6 students in the Hulu Langat district discovered that primary children do not place a premium on the quality of the paper in a textbook as long as other layout requirements, such as chapter components or colour, are met.

This research has important ramifications for educators. There must be a coordinated national effort to assist students in becoming significantly, if not completely, self-sufficient consumers of school texts. Reduce reliance on instructors as lesson mediators by eliminating the need to take notes on unneeded, long extracts from school-required textbooks. Additionally, there is a demand for more engaging and interactive textbooks. This need may be met by concentrating on the physical characteristics of elementary school textbooks without diminishing the significance of excellent textbook content. There are also clear consequences for textbook designers, who must adapt to advancements in publishing, instructional design, and educational technology by transitioning to the digital platform.

\section{References}

Ahmadi, H., Yazdani, S., Babasalari, Z., \& Rabi, A. (2019). Representation meaning of multimodal discourse in textbooks: A case study of Persian Language-Learning Textbook. Higher Education of Social Science, 16(1), $12-21$.

Ansary, H., \& Babaii, E. (2002). Universal characteristics of EFL/ESL textbook: A step towards systematic textbook evaluation. The Internet TESL Journal, 2, 1-8.

Bond, T. G., \& Fox, C. M. (2015). Applying The Rasch Model Fundamental Measurement in the Human Science (3rd ed.). (Routledge \& T. \& F. Group, Eds.)

Eitel, A. et al. (2013). How a picture facilitates the process of learning from text: Evidence for scaffolding. Learning and Instruction, 28, 48-63. https://doi.org/10.1016/j.learninstruc.2013.05.002

Geertsen, R. (1977). The textbook: An ACIDS test. Teaching Sociology, 5(1), 101-120. https://doi.org/10.2307/1316938

Giordano, G. (1982). How complex is your textbook? The Clearing House, 55(8), 369-373. https://doi.org/10.1080/00098655.1982.10113702

Gopinathan, S. (1983). The role of textbooks in Asian education. Prospects, 13(3), 343-350. https://doi.org/10.1007/BF02220428

Harp, S. F., \& Mayer, R. E. (1997). The role of interest in learning from scientific text and illustrations: On the distinction between emotional interest and cognitive interest. Journal of Educational Psychology, 89(1), 92-102. https://doi.org/10.1037/0022-0663.89.1.92

Hewitt, J. (1973). Choosing a textbook. Mathematics in School, 2(1), 2-3. 
Landrum, R. E., \& Clark, J. (2006). Student perceptions of textbook outlines. College Student Journal, 40(3), 646-650.

Landrum, R. E., Gurung, R. A., \& Spann, N. (2012). Assessments of textbook usage and the relationship to $\begin{array}{lllll}\text { student course } & \text { performance. }\end{array}$ https://doi.org/10.1080/87567555.2011.609573

Lavrenko, V. (2008). A generative theory of relevance (Vol. 26). Springer Science \& Business Media.

Linacre, J. M. (2005). Test Validity and Rasch Measurement: Construct, Content, etc.

Mayer, R. E., Steinhoff, K., Bower, G., \& Mars, R. (1995). A generative theory of textbook design: Using annotated illustrations to foster meaningful learning of science text. Educational Technology Research and Development, 43(1), 31-41. https://doi.org/10.1007/BF02300480

Miller, W. R., \& Berry, R. H. (1962). Adopting the right textbook. The Clearing House, 37(1), 18-23. https://doi.org/10.1080/00098655.1962.11476201

Nicholls, J. (2003). Methods in school textbook research. University of Exeter. https://doi.org/10.18546/HERJ.03.2.02

Neill, R. O. (1982). Why use textbooks? ELT Journal, 36(2), 104-111. https://doi.org/10.1093/elt/36.2.104

Rezat, S. (2006). A model of textbook use. Psychology of Mathematics Education, 4, 409-416.

Smith, K. U. (1960). The scientific principles of textbook design and illustration. Audio-Visual Communication Review, 8(1), 27-49. https://doi.org/10.1007/BF02713372

Tok, H. (2010). TEFL textbook evaluation: From teachers perspectıves. Educational Research and Reviews, 5(9), 508-517.

Vellenga, H. (2004). Learning Pragmatics from ESL \& EFL Textbooks: How Likely?. Tesl-Ej, 8(2), n2.

Weinberg, A., \& Wiesner, E. (2011). Understanding mathematics textbooks through reader-oriented theory. Educational Studies in Mathematics, 76(1), 9-63. https://doi.org/10.1007/s10649-010-9264-3

Weiten, W., Guadagno, R. E., \& Beck, C. A. (1996). Students' perceptions of textbook pedagogical aids. Teaching of Psychology, 23(2), 105-107. https://doi.org/10.1207/s15328023top2302_8

Yusof, R. (2004). Social Science Research. Bentong, Pahang.

\section{Copyrights}

Copyright for this article is retained by the author(s), with first publication rights granted to the journal.

This is an open-access article distributed under the terms and conditions of the Creative Commons Attribution license (http://creativecommons.org/licenses/by/4.0/). 